\title{
Four or More Cesarean Sections, Is It Still Safe?
}

\author{
Burak YÜCEL ${ }^{1}$, Pınar KADİROĞULLARI'1, Onur KARAASLAN'1, Turgut AYDIN², Kerem Doğa SEÇKİN \\ Ali GEDÍKBAŞI ${ }^{1}$
}

Istanbul, Turkey

ABSTRACT

OBJECTIVE: We aimed to compare the maternal and neonatal complications in women who had undergone fourth or more cesarean section with to women who had undergone second or third cesarean section.

STUDY DESIGN: 162 women who had four or more cesarean section (study group) and 228 women who had undergone second or third cesarean section (control group) were reviewed retrospectively. Demographic features, obstetric, intraoperative, postpartum and neonatal complications were determined in both groups.

RESULTS: The preoperative hematocrit values were lower in study group $(35.6 \pm 3.6)$ than the control group $(36.6 \pm 4.3),(p<0.001)$. Patients with four or more cesarean sections had an increased rate $(24.7 \%)$ of intra-abdominal dense adhesions compared with the controls $(14.9 \%),(p<0.001)$. Blood transfusion rate was higher in the study group $(8.6 \%$ to $3.5 \%, p=0.043)$. Except these; frequencies of obstetric, intraoperative, postpartum and neonatal complications were similar between groups.

CONCLUSION: We found that multiple CSs (four or more) do not increase the risk of maternal or neonatal complications except the rate of maternal anemia, dense adhesions and need for blood transfusion according to the results of our study. Fourth or more cesarean section appears to be still a safe procedure.

Keywords: Cesarean section, Repeat cesarean section, Maternal complications, Neonatal complications, Vaginal birth after cesarean

Gynecol Obstet Reprod Med 2017;23(3):133-137

\section{Introduction}

The rate of cesarean section (CS) deliveries has increased dramatically worldwide in the last decades (1). Turkey is one of the countries performing high levels of CS. The number of

\footnotetext{
${ }^{1}$ Clinic of Obstetrics and Gynecology Kanuni Sultan Suleyman Research and Training Hospital, Istanbul

${ }^{2}$ Department of Obstetrics and Gynecology, Aclbadem University School of Medicine, Atakent Hospital, Istanbul

Address of Correspondence: Burak Yücel

Kanuni Sultan Süleyman Eğitim ve Araştırma Hastanesi Atakent Mh. Turgut Ozal Cd. No:1 34303 Altınşehir,

Küçükçekmece, Istanbul, Turkey drburakyucel@gmail.com

Submitted for Publication:

14.02.2017

Accepted for Publication:

28.03 .2017
}

\begin{tabular}{|c|c|}
\hline & Access this article online \\
\hline $\begin{array}{c}\text { Quick Response Code: } \\
\text { 口a }\end{array}$ & Website: www.gorm.com.tr \\
\cline { 2 - 3 } & DOI:10.201613/GORM.2017.677 \\
\hline
\end{tabular}

How to cite this article: Yücel B. Kadiroğulları P. Karaaslan O. Aydın T. Doğa Seçkin K. Gedikbașl A. Four or More Cesarean Sections, is it Still Safe? Gynecol Obstet Reprod Med 2017;23(3):133-137
CS deliveries has been reached to $41 \%$ among all deliveries in nowadays (2). The increase continues to evoke worldwide concern because of the steady, lack of consensus on the appropriate CS rate and the associated additional short and long term risks and costs. The most common explanation is the growing number of women with prior CSs (3). It may also be explained with an indication of reduced maternal and infant morbidity and mortality. However, there is no enough evidence whether maternal or child health has benefited from this increase (4).

Although, CS can be a lifesaving operation when either mother or her infant face problems during pregnancy or delivery, it is a major abdominal surgery and is associated with immediate maternal and perinatal risks and may have implications for future pregnancies. These include risks of anesthesia, hemorrhage, damage to adjacent organs, embolism, infections, placental invasion abnormalities, occurrences of intraabdominal adhesions, uterine rupture or neonatal morbidity and mortality (5).

Generally, CS delivery are not recommended after three CSs by many obstetricians. However, research has not established the exact number of repeat CSs considered safe (6). 
There are limited studies in the literature that report maternal and fetal complication rates in women who have had fourth or more than four CSs (7-9).

In this study, we aimed to compare the maternal and neonatal complications in women who had four or more CSs with to women who had fewer repeated (two or three) CS.

\section{Material and Method}

This study was conducted in the Clinic of Obstetrics and Gynecology of Kanuni Sultan Suleyman Research and Training Hospital that is a third level reference hospital with around eighteen thousand deliveries each year. A retrospective analysis of the hospital records has been performed. Third hundred and ninety women between January 2016 and August 2016 were included to the study. One hundred and sixty-two women who had four or more CS comprised the study group. Two hundred and twenty-eight women who had one or two prior CS were selected among patients as control group.

The inclusion criteria were patients who had undergone at least one CS, and the presence of complete patient data such as information on surgery and follow-up. Demographic and clinical features, including age, gravidity and numbers of previous $\mathrm{CS}$ and vaginal deliveries, gestational age at delivery, their race, demand for tubal ligation, preoperative and postoperative hematocrit values and type of anesthesia data were obtained. Obstetric, intraoperative, postpartum and neonatal complications were determined separately in the study and control groups. Indications for emergency (non-elective) CS were pain, rupture of membranes, bleeding, hypertension and fetal distress.
Assessment of dense adhesions was carried out as previously described in literature (3): Dense adhesion was defined as the presence of adhesions (i) extending from the abdominal wall to the bladder or to the front wall of the uterus, (ii) not separating easily and (iii) left alone during surgery due to the concern that it could cause serious morbidity.

\section{Statistical analysis}

Data analysis was performed using SPSS Statistics for Macintosh version 20.0 (IBM Corporation, Armonk, NY, USA). The One-Sample Kolmogorov-Smirnov test was used to determine compliance of the data to normal distribution and Levene's test was used to determine homogeneity of variance. Quantitative data with normal distribution are expressed as mean \pm standard deviation (SD). Quantitative data with abnormal distribution expressed as median (minimum-maximum). To compare parametric continuous variables, the Student $\mathrm{T}$ test was used; to compare nonparametric continuous variables, the Mann-Whitney U test was used. Categorical data are given as number (n) and percentage (\%). Fisher's exact test were implemented on categorical variables. $\mathrm{p}<0.05$ was considered statistically significant.

\section{Results}

The demographic and clinical features of the study and control groups are presented in table 1 . The maximum number of CSs was seven in this study. Maternal age, gravidity, previous CS and vaginal deliveries and demand for tubal ligation were higher in study group. There were no differences between groups in the terms of gestational week at delivery, race and type of anesthesia. The preoperative hematocrit values

Table 1: Patients demographics

\begin{tabular}{|c|c|c|c|c|}
\hline & & $\begin{array}{c}\text { Control group } \\
\text { (Second or third cesarean section) }\end{array}$ & $\begin{array}{c}\text { Study group } \\
\text { (Fourth or more cesarean section) }\end{array}$ & $\begin{array}{c}p \\
\text { Value }\end{array}$ \\
\hline \multicolumn{2}{|l|}{ Number of patients } & 228 & 162 & \\
\hline \multicolumn{2}{|l|}{ Age } & $28.2 \pm 4.4$ & $31.5 \pm 4.9$ & $<0.001^{*}$ \\
\hline \multicolumn{2}{|l|}{ Gravidity } & $3[2-12]$ & $4[4-8]$ & $<0.001^{* *}$ \\
\hline \multicolumn{2}{|c|}{ Previous cesarean section } & $1[1-2]$ & $3[3-6]$ & $<0.001^{* *}$ \\
\hline \multicolumn{2}{|c|}{ Previous vaginal delivery } & $0[0-7]$ & 0 [0-3] & $<0.001^{* *}$ \\
\hline \multicolumn{2}{|c|}{ Gestational week at delivery } & 38 [23-42] & $38[25-41]$ & $0.358^{* *}$ \\
\hline \multirow{2}{*}{ Race } & Turkish & 201 & 138 & \multirow{2}{*}{$0.447^{* * *}$} \\
\hline & Syrian & 27 & 90 & \\
\hline \multirow{2}{*}{ Type of anesthesia } & General & 118 & 90 & \multirow{2}{*}{$0.473^{* * *}$} \\
\hline & Regional & 110 & 72 & \\
\hline \multicolumn{2}{|c|}{ Demand for tubal ligation } & $20(8.8 \%)$ & $48(29.6 \%)$ & $<0.001^{* * *}$ \\
\hline \multicolumn{2}{|c|}{ Emergency cesarean section } & $123(53.9 \%)$ & $97(59.9 \%)$ & $0.126^{* * *}$ \\
\hline \multicolumn{2}{|c|}{ Preoperative hematocrit values } & $36.6 \pm 4.3$ & $35.6 \pm 3.6$ & $0.041^{*}$ \\
\hline
\end{tabular}

The $p$-values are bold where they are less than or equal to the significance level cut-off of 0.05 .

* Student $T$ test, ${ }^{* *}$ Mann-Whitney $U$ test, ${ }^{* * *}$ Fisher's Exact test 
were lower in women with four or more $(35.6 \pm 3.6)$ than the control group (36.6 \pm 4.3$)$. The difference was statistically significant $(\mathrm{p}<0.001)$.

Complication rates of patients in both groups are presented in table 2. The incidence of obstetrics complications, such as preterm delivery, gestational diabetes, intrauterine growth restriction and preeclampsia were similar in both groups. Patients with four or more CS had an increased rate (24.7\%) of intra-abdominal dense adhesions compared with the controls $(14.9 \%),(p<0.001)$. No clinical uterine rupture was observed in any patient. Rate of other intraoperative complications, such as, subclinical uterine rupture, placental invasion abnormalities and bladder or bowel injury were similar in both groups. There were no differences between groups in the terms of postoperative hematocrit values and the difference between post and preoperative hematocrit values. Postpartum and neonatal complications were similar in the groups.

\section{Discussion}

There has been a significant increase in the CS rate in Turkey as in world-wide (9). Previously in the literature, it has been shown that repeated cesarean birth was related to serious maternal and fetal complications when compared to normal birth and the first CS (10). However, Lynch et al. found no correlation between repeated CSs and maternal morbidity (11). Uygur et al. reported that post-operative complications have no correlation with the number of previous CSs (12). In this study, we did not observe any significant rise in obstetrics, intraoperative, postpartum or neonatal complications except increased risk of intra-abdominal dense adhesions, anemia

Table 2: Complication rates of patients in both groups

\begin{tabular}{|c|c|c|c|c|}
\hline & & $\begin{array}{l}\text { Control group } \\
\text { (Third or second cesarean } \\
\text { section) } \\
(n=228)\end{array}$ & \begin{tabular}{|c} 
Study group \\
(Fourth or more cesarean sec- \\
tion) \\
$(n=162)$
\end{tabular} & $\begin{array}{c}p \\
\text { Value }\end{array}$ \\
\hline \multirow{4}{*}{ 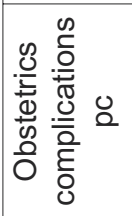 } & Preterm delivery & $34(14.9 \%)$ & $21(12.9 \%)$ & $0.659^{* * *}$ \\
\hline & Gestational diabetes & $10(4.4 \%)$ & $7(4.3 \%)$ & $1^{* \star *}$ \\
\hline & Intrauterine growth restriction & $6(2.6 \%)$ & $5(3.1 \%)$ & $0.768^{* * *}$ \\
\hline & Preeclampsia & $8(3.5 \%)$ & $5(3.1 \%)$ & $1^{* * *}$ \\
\hline \multirow{8}{*}{ 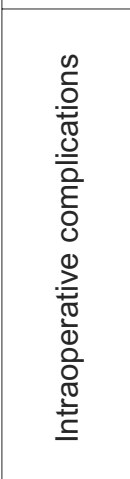 } & Intra-abdominal dense adhesions & $34(14.9 \%)$ & $40(24.7 \%)$ & $0.018^{* * *}$ \\
\hline & Subclinical uterine rupture & $2(0.9 \%)$ & $6(3.7 \%)$ & $0.071^{* * *}$ \\
\hline & Placenta previa & $4(1.8 \%)$ & $6(3.7 \%)$ & $0.331^{* * *}$ \\
\hline & Placenta accreta & $2(0.9 \%)$ & $6(3.7 \%)$ & $0.07^{* * *}$ \\
\hline & Bladder injury & $1(0.4 \%)$ & $3(1.9 \%)$ & $0.312^{* * *}$ \\
\hline & Bowel injury & 0 & $1(0.6 \%)$ & $0.415^{\star * *}$ \\
\hline & Cesarean hysterectomy & 0 & $2(1.2 \%)$ & $0.172^{* * *}$ \\
\hline & $\begin{array}{l}\text { Difference between preoperative and } \\
\text { postoperative hematocrit values }\end{array}$ & $4.7 \pm 2.6$ & $4.2 \pm 2.7$ & $0.175^{*}$ \\
\hline \multirow{4}{*}{ 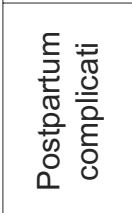 } & Postoperative hematocrit values & $31.9 \pm 4.2$ & $31.4 \pm 4.1$ & $0.26^{*}$ \\
\hline & Blood transfusion & $8(3.5 \%)$ & $14(8.6)$ & $0.043^{* * *}$ \\
\hline & Hospital stay & $2[2-7]$ & $2[2-10]$ & $0.721^{* *}$ \\
\hline & Wound infection & $2(0.9 \%)$ & $4(2.5 \%)$ & $0.238^{\star * *}$ \\
\hline \multirow{5}{*}{ 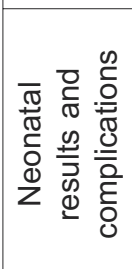 } & Apgar 1. Minute & $8[0-10]$ & $8[0-10]$ & $0.881^{* *}$ \\
\hline & Apgar 5. Minute & $9[0-10]$ & $9[0-10]$ & $0.905^{\star *}$ \\
\hline & Birthweight & $3121 \pm 643.2$ & $3091.5 \pm 583.1$ & $0.605^{*}$ \\
\hline & Intensive care unit admission & $18(7.9 \%)$ & $14(8.6 \%)$ & $0.852^{* * *}$ \\
\hline & Neonatal death & $2(0.9 \%)$ & $3(1.9 \%)$ & $0.378^{* * *}$ \\
\hline
\end{tabular}

The p-values are bold where they are less than or equal to the significance level cut-off of 0.05 .

* Student $T$ test, ${ }^{* *}$ Mann-Whitney $U$ test, ${ }^{* * *}$ Fisher's Exact test 
and need for the blood transfusion in women who had four or more CS compared to controls who had one or two prior CS.

Increased maternal age and high parity is reported to be risk factors for poor maternal and perinatal outcome such as, anemia during pregnancy, gestational diabetes, intrauterine growth restriction (13). The majority of the studies argued that grand multiparas are more likely to be of old age which might be the reason for increased morbidity and mortality (14). Conversely, it has been defined that nulliparous mothers had an increased risk of preterm birth and preeclampsia compared to multiparous women (15). In the present study, women who had 4 or more CS were older and had higher gravidity (31.5 \pm 4.9 and 4 [4-8], respectively) than the controls who had two or less CS (28.2 44.4 and 3 [2-12], respectively) $(\mathrm{p}<0.001)$. Preoperative hematocrit values were significantly lower in study group compared to control group. Multiparty responsible for the severity of anemia during pregnancy. In addition, repeated CSs as major surgery contributes to the anemia in these patients. Similar to literature, preterm birth and preeclampsia were lower, gestational diabetes and intrauterine growth restriction were higher in the study group in our study. However, there were no statistically significant difference between obstetrics complications that listed above in groups. A possible explanation for this disagreement can be the difference in the sample size of the study and the control group, which is smaller in our study, and did not provide a statistical power for the accurate rate.

Abdominal and pelvic adhesions are fibrous, band-like structures that form between abdominal organs or between the peritoneum and abdominal wall when prior surgeries induces inflammation and disrupts normal tissue (6). Adhesions are common after cesarean births. The reported incidence of adhesion development after primary CS ranges from \%10-40 (16). In addition to differences in size and location density of adhesions can vary greatly. Some adhesions are easily separable and filmy in density; other adhesions are thick and dense, particularly after multiple repeat CSs (17). A higher number of $\mathrm{CSs}$ is related to increasing frequency of adhesion development: In the literature, adhesion rates are $12-46 \%$ in patients who have undergone two CSs, and $26-75 \%$ in those with three previous CSs (4). Moreover, Rashid et al. found that the rate in patients who had five or more CSs was 54\% (7). In present study, we observed that the dense adhesion rate of those who had undergone two or one prior CS was $14.9 \%$, while this was $24.7 \%$ for patients who had fourth or more CS. This rate was statistically significant $(\mathrm{p}<0.001)$, and was also consistent with the literature.

Uterine rupture at the site of a previous CS scar is an uncommon but catastrophic complication of pregnancy. Uterine ruptures could be divided into complete and incomplete or dehiscence ruptures. Full thickness tears of uterine wall result in complete uterine ruptures. In incomplete uterine rupture or de- hiscence, the myometrium is disrupted but the serosa is intact (18). Complete uterine rupture was not occurred in both groups, however, dehiscence of CS was more common in study group $(3.7 \%)$ compared to controls $(0.9 \%)$, but the difference was not statistically significant. Abnormal placental invasion following repeated $\mathrm{CS}$ is concurrent with an increased risk of placenta previa and placenta accreta (19). The risk of placenta previa has been reported to increase by 0.28 $2 \%$ in patients who have undergone at least $1 \mathrm{CS}$ in a systemic review, especially for placenta previa (17). The incidence of placental invasion abnormalities increased with the increasing number of CSs. Marshall et. al found that women with one previous CS had a rate of accreta of 0.3-0.6\%. The incidence of accreta continued to rise with increasing previous $\mathrm{CD}$ up to $6.74 \%$ for women with 5 or more CSs (17). We found that both rates of placenta previa $(3.7 \%$ to $1.8 \%)$ and accreta $(3.7 \%$ to $0.9 \%$ ) were more common in women with four or more CS. This result correlates with the literature data, however, the difference was not statistically significant. Cesarean hysterectomy was performed in one case due to atony and the other one due to placenta accreta in the study group. Segmental myometrial resection was performed for remaining patients with placenta accreta in both groups. The rate of bladder or bowel injury did not differ between groups. Gasim et al. found that patients had increased blood loss and need for blood transfusion in pregnant women with four or more CSs compared with a control group of women having 2-3 CSs (8). In our study, difference between preoperative and postoperative hematocrit values, as a sign of operative blood loss, were similar in both groups. Rate of blood transfusion was higher in the study group. This should be due to the lower preoperative hematocrit values of this group. Wound infection were more prevalent and day of the hospital stay was longer in women with 4 or more CS, however, there were no significant differences between the groups. We found no difference between groups in neonatal results, such as 1., 5. Apgar scores and birthweights of infants; or neonatal complications such as intensive care unit admission and neonatal death.

In recent years; however, vaginal birth after CS has become popular option to help reduce multiple CS rates, it is with increased risks such as uterine rupture. The uterine rupture during vaginal birth after $\mathrm{CS}$ incidence ranged from $0.15 \%$ to $2.3 \%$ in the literature (20). As it shown in our study, repeated CSs remain a safe procedure without increased maternal and neonatal complications. Obstetricians should decide carefully when recommending vaginal birth after CS to their patients.

Being a single-center study and including a relatively low number of patients may be regarded as a limitation. Well defined study and control groups and given the result of a tertiary reference hospital are major advantages of our study.

In conclusion, we found that multiple CSs (four or more) 
do not increase the risk of maternal or neonatal complications except the rate of maternal anemia, dense adhesions and need for blood transfusion according to the results of our study. Fourth or more CS appears to be still a safe procedure, however, this conclusion needs to be confirmed with researches of large cohorts on this issue.

\section{References}

1. Arikan DC, Coskun A, Ozer A, Kiran H, Tok A, Zencir E. Impact of cesarean section number on maternal and obstetric outcome. Gynecol Obstet Reprod Med 2009;15(3):144-7.

2. Yılmaz E, Kara M, Okumuş B, Aran E. The statistics of four years cesarean and normal spontaneus vaginal delivery of our clinic. Turk J Obstet Gynecol 2008;5:253-7.

3. Akarsu RH, Mucuk S. Turkish women's opinions about cesarean delivery. Pak J Med Sci 2014;30(6):1308-13.

4. Kaplanoglu M, Bulbul M, Kaplanoglu D, Bakacak SM. Effect of multiple repeat cesarean sections on maternal morbidity: data from southeast Turkey. Med Sci Monit 2015;21:1447-53.

5. Çağlayan EK, Kara M, Gürel YC. Evaluation of risk factors and potential complications after cesarean operations in our clinic. Med J Bakırköy 2011;7(2):64-67

6. Lyell DJ. Adhesions and perioperative complications of repeat cesarean delivery. Am J Obstet Gynecol 2011; 205(6 Suppl):11-18.

7. Rashid M, Rashid RS. Higher order repeat caesarean sections: how safe are five or more? BJOG 2004;111(10): 1090-4.

8. Gasim T, Al Jama FE, Rahman MS, Rahman J. Multiple repeat cesarean sections: operative difficulties, maternal complications and outcome. J Reprod Med 2013;58(78):312-8.

9. Uyanikoglu H, Karahan MA, Turp AB, Agar M, Tasduzen $\mathrm{ME}$, Sak S, et al. Are multiple repeated cesarean sections really as safe? J Matern Fetal Neonatal Med 2017;30(4):482-5.

10. Kok N, Ruiter L, Hof M, Ravelli A, Mol BW, Pajkrt E, et al. Risk of maternal and neonatal complications in subsequent pregnancy after planned caesarean section in a first birth, compared with emergency caesarean section: a nationwide comparative cohort study. BJOG 2014;121 (2):216-23.

11. Lynch CM, Kearney R, Turner MJ. Maternal morbidity after elective repeat caesarean section after two or more previous procedures. Eur J Obstet Gynecol Reprod Biol 2003;106(1):10-3.

12. Uygur D, Gun O, Kelekci S, Ozturk A, Ugur M, Mungan T. Multiple repeat caesarean section: is it safe? Eur J Obstet Gynecol Reprod Biol 2005;119(2):171-5.

13. Kenny LC, Lavender T, McNamee R, O'Neill SM, Mills T, Khashan AS. Advanced maternal age and adverse pregnancy outcome: evidence from a large contemporary cohort. PLoS One 2013;8(2):e56583.

14. Alsammani MA, Ahmed SR. Grand Multiparity: Risk Factors and Outcome in a Tertiary Hospital:a Comparative Study. Mater Sociomed 2015;27(4):244-7.

15. Bdolah Y, Elchalal U, Natanson-Yaron S, Yechiam H, Bdolah-Abram T, Greenfield C, et al. Relationship between nulliparity and preeclampsia may be explained by altered circulating soluble fms-like tyrosine kinase 1 . Hypertens Pregnan 2014;33(2):250-9.

16. Hamel KJ. Incidence of adhesions at repeat cesarean delivery. Am J Obstet Gynecol 2007;196(5):e31-2.

17. Marshall NE, Fu R, Guise JM. Impact of multiple cesarean deliveries on maternal morbidity: a systematic review. Am J Obstet Gynecol 2011;205(3):262 e1-8.

18. Ahmadi F, Siahbazi S, Akhbari F. Incomplete cesarean scar rupture. J Reprod Infertil 2013;14(1):43-5.

19. Odibo AO, Cahill AG, Stamilio DM, Stevens EJ, Peipert JF, Macones GA. Predicting placental abruption and previa in women with a previous cesarean delivery. Am J Perinatol 2007;24(5):299-305.

20. Holmgren C, Scott JR, Porter TF, Esplin MS, Bardsley T. Uterine rupture with attempted vaginal birth after cesarean delivery: decision-to-delivery time and neonatal outcome. Obstet Gynecol 2012;119(4):725-31. 